Running head: Powering Sustainable Consumption

\title{
Powering Sustainable Consumption: The Roles of Green Consumption Values and Power
}

\section{Distance Belief}

\author{
Li Yan \\ UTS Business School \\ University of Technology Sydney \\ PO Box 123, Broadway NSW 2007, Australia \\ Phone: +61 2 9514-3265 \\ Email: Li.Yan@uts.edu.au \\ Hean Tat Keh \\ Monash Business School \\ Monash University \\ Caulfield East, VIC 3145, Australia \\ Phone: +61 3 9903-1155 \\ Email: ht.keh@monash.edu \\ Xiaoyu Wang \\ College of Business \\ Shanghai University of Finance and Economics \\ Shanghai 200433, China \\ Tel: +86-21-65904624 \\ Email: twwz2002@aliyun.com
}

Forthcoming in Journal of Business Ethics (FT50 journal).

\begin{abstract}
All authors declare that they have no conflict of interest. This study was funded by the research incentive grant (1764979) awarded to Hean Tat Keh by Monash University, and the research grant (2210209) awarded to Li Yan by the University of Technology Sydney. Part of this research was conducted at the Monash Business Behavioral Laboratory. The first two authors contributed equally. Please address all correspondence to Hean Tat Keh.
\end{abstract}

Please cite as: Yan, Li, Hean Tat Keh, and Xiaoyu Wang, "Powering Sustainable Consumption: The Roles of Green Consumption Values and Power Distance Belief," Journal of Business Ethics, forthcoming. 


\title{
Powering Sustainable Consumption: The Roles of Green Consumption Values and Power Distance Belief
}

\begin{abstract}
As human consumption is one of the key contributors to environmental problems, it is increasingly urgent to promote sustainable consumption. Drawing on the agentic-communal model of power, this research explores how the psychological feeling of power influences consumers' preference for green products. We show that low power increases consumers' preference for green (vs. conventional) products compared to high power (Studies 1a and 1b). Importantly, we identify two factors moderating the main effect of power on green consumption. Specifically, we find that the effect of power on green consumption is more salient among those with high green consumption values (Study 2). In addition, the effects of power are dynamic as a function of power distance belief (PDB), such that low power (vs. high power) promotes green consumption in the low-PDB context while high power (vs. low power) promotes green consumption in the high-PDB context (Study 3). Taken together, these findings provide novel insights into understanding green consumption from the perspectives of social power, green values, and PDB. Besides contributing to the literature, the findings have significant implications for marketers and policy-makers in promoting green campaigns, bridging the attitude-behavior gap, and building a more sustainable society.
\end{abstract}

Keywords: social power, sustainable consumption, green products, power distance belief 


\section{Introduction}

Many of the existing environmental problems can be attributed to individual and household consumption activities (European Commission 2012; EEA 2012; Trudel 2019; Van Vugt 2009). One of the ways to ameliorate environmental degradation is to switch the consumption of conventional products to their green alternatives (Griskevicius et al. 2010; Haws et al. 2014; Sachdeva et al. 2015). Green products are those manufactured to minimize the exploitation of natural resources, the use of toxic materials, or the emission of waste and pollutants (Amatulli et al. 2019). Nonetheless, despite the increasing availability of green product alternatives in the market (Lin and Chang 2012; Romani et al. 2016), consumers show great variation in their acceptance of green products (Carrington et al. 2010, 2014; Gleim et al. 2013; Luchs et al. 2010; Olson 2013; Pancer et al. 2017). Thus, there is an urgent need to better understand how to effectively mobilize consumers to embrace green products (Barbarossa and De Pelsmacker 2016; Haws et al. 2014).

Prior research has documented factors influencing green consumption from product, consumer, society, firm and policy-maker perspectives (Antonetti and Maklan 2014; Brough et al. 2016; Choi and Ng 2011; Gleim et al. 2013; Newman et al. 2014; Prothero et al. 2011; Thøgersen 2005; White and Simpson 2013). The literature suggests that consumers' decisionmaking toward environmental issues is complex, malleable, and influenced by social and psychological factors (Gifford 2014; Van Vugt 2009; Weber 2015; Zaval et al. 2015), such as their status in the social hierarchy (Griskevicius et al. 2010; Zabkar and Hosta 2013).

In extending the literature, the present research examines the effects of social power on green consumption. Social power is one of the most pervasive and ubiquitous psychological forces shaping human behavior (Fiske and Berdahl 2006; Keltner et al. 2003; Magee and Smith 2013). Although social status and power represent two fundamental aspects of the social 
hierarchy, they are different in that status is based on reputation, while power is often defined as perceived asymmetric control over valued resources or other people in social relations (Magee and Galinsky 2008; Rucker et al. 2012). Central to the definition of social power is the notion of relative control over valued resources (Rucker and Galinsky 2017), implying resource discrepancy and inequality between low- and high-power individuals (Kraus et al. 2012). Notably, individuals may feel powerful/powerless chronically or dynamically in their daily lives (Anderson et al. 2012; Rucker, Hu, and Galinsky 2014).

Drawing on the agentic-communal model of power (Rucker et al. 2012), we propose that low- and high-power consumers respond to green and conventional products differently, such that low-power consumers have greater preference for green (vs. conventional) products compared to their high-power counterparts. Furthermore, green consumption is influenced by consumers' core values, beliefs, and contextual factors (Gifford 2014; Sachdeva et al. 2015). Thus, we further propose two boundary conditions for this effect; one based on their green consumption values, and the other based on their belief pertaining to power disparity.

Specifically, research advocating value-consistent sustainable behaviors emphasizes congruity between consumers' personal well-being and behaviors benefiting the environment (Sheth et al. 2011; Weber 2015). In this vein, Haws et al. (2014) propose the concept of green consumption values (i.e., GREEN values) that reflect the alignment of resource conservation at the personal level with societal benefits through their green behavior. It reflects the extent to which consumers effectuate their value importance on sustainability into actual product choice. Not surprisingly, green consumers tend to have high GREEN values. To this end, recent research shows that consumers could be targeted with green marketing communications based on their GREEN values (Bailey, Mishra, and Tiamiyu 2018). Nonetheless, more research is needed to explore the potential interaction of GREEN values with other resource-related concepts (e.g. 
wealth and power) for a more nuanced understanding on green consumption behaviors (Haws et al. 2014). Prior research shows that sustainability importance moderates consumers' choice between green and conventional products (Luchs et al. 2012). In this vein, we propose that GREEN values can moderate the effect of power on green consumption, such that high (vs. low) GREEN values will enhance (vs. attenuate) the effect of power on green consumption.

Moreover, the expression and enactment of power differ across cultures (Han et al. 2017; Oyserman 2006; Torelli and Shavitt 2010; Zhong et al. 2006). In particular, consumers' attitudes toward power disparity may vary, regardless of their actual power states, such that some are more accepting of power disparity compared to others (Hofstede 2001; Zhang et al. 2010). Thus, we further explore the moderating effect of power distance belief (PDB) in the relationship between power and green consumption. We propose that low power (vs. high power) promotes green consumption in the low-PDB context while high power (vs. low power) promotes green consumption in the high-PDB context. In this vein, we show that the effect of power on propensity for green consumption varies as a function of PDB.

Through investigating these two boundary conditions, this research provides a nuanced understanding of the malleable effects of social power on consumers' propensity for green consumption. Our findings contribute to the literatures on power and green consumption, as well as have important practical implications. We next review the literature and develop testable hypotheses. Following that, we conduct four experimental studies to test the hypotheses. Finally, we discuss the theoretical and practical implications, and suggest directions for future research.

\section{Theoretical Background and Hypotheses Development}

\section{Sustainability and green consumption}

It has been observed that environmental issues such as climate change and global 
warming are largely due to greenhouse gases produced by human activities (Trudel 2019).

Human activities are also responsible for depleting natural resources and environmental pollution (Van Vugt 2009). As every consumer's decision of what to buy, how much to buy, how much to consume, and how to dispose has a direct impact on the environment, the cumulative effect of human consumption activities on the environment is devastating (Trudel 2019). Thus, it has become imperative to identify ways to enhance sustainable or green consumption behaviors (Brough et al. 2016; Gifford 2014; Gleim et al. 2013; Sachdeva et al. 2015). One of the critical ways is to shift individuals' consumption pattern from conventional products to green products (Griskevicius et al. 2010; Haws et al. 2014).

In this article, a green product refers to one that is produced with concern for the physical environment: air, water, and land (Shrum et al. 1995). Thus, we define green consumption as consumers' preference or choice for green products. Specifically, green consumers tend to favor environmentally-friendly products to minimize the potentially negative environmental impact from their purchases, while non-green consumers tend to prefer conventional products even when environmentally-friendly alternatives are available (Gleim et al. 2013; Haws et al. 2014).

In reality, while consumers are generally aware of the importance of going green, not all consumers are willing to forego price, quality, and convenience for a product's "greenness" (Carrington et al. 2014; Luchs et al. 2010; Olson 2013). To this end, prior research has studied green consumption from diverse perspectives (Trudel 2019). The first stream explores productrelated factors such as package color, ecolabels, price, and product functions (Luchs et al., 2010; Pancer et al. 2017; Seo and Scammon 2017; Thøgersen et al. 2010). The findings suggest that consumers make trade-offs during their purchase decisions, such as between sustainability and price (Choi and Ng 2011), between sustainability and functionality (Luchs et al. 2010; 2012), and between product efficacy and social benefits (Newman et al. 2014). Relatedly, a second 
stream of research investigates firm-level factors such as perceived corporate intentions and social responsibility initiatives (Choi and Ng 2011; Newman et al. 2014; Romani et al. 2016).

Of particular interest to us is the third stream of research focusing on consumer-related factors. Researchers are concerned about the "green intention-behavior gap," whereby consumers' positive attitudes and intentions toward green consumption often do not translate into actual green behaviors (Carrington et al. 2010, 2014; Gleim et al. 2013; Olson 2013). In this vein, some researchers examine the cognitive and emotional factors underlying how consumers process green information, including message/ad framing, message assertiveness, perceived guilt, pride (Amatulli et al. 2019; Antonetti and Maklan 2014; Kronrod et al. 2012; Theotokis and Manganari 2015), information elaboration and psychological distance (Tangari et al. 2015), as well as regulatory focus (Bullard and Manchanda 2013).

Other researchers turn to social influences for explanation, examining how social norms (White and Simpson 2013) and status motives (Griskevicius et al. 2010) influence green consumption. In particular, prior research suggests that status motives could promote green consumption (Griskevicius et al. 2010; Zabkar and Hosta 2013). Nonetheless, such status-related “going green to be seen" behavior does not reflect intrinsically green consumption. For example, high-status "green" shoppers are more likely to keep buying new bags rather than bring their own shopping bags compared to lower-status shoppers (Van der Wal et al. 2016).

Yet other researchers examine consumers themselves, including the effects of their gender stereotype, self-identity, knowledge, political ideology, and values on green consumption (Bailey et al. 2018; Brough et al. 2016; Haws et al. 2014; Kidwell et al. 2013). This line of research includes identifying or profiling green segments based on sociodemographic and psychographic variables (Barbarossa and De Pelsmacker 2016; Diamantopoulos et al. 2003). Notwithstanding these efforts, more research is needed to better understand how to shift 
consumers' preference for conventional products to green alternatives (Haws et al. 2014; Pancer et al. 2017; Sachdeva et al. 2015). Accordingly, the present research examines how the psychological feeling of social power influences green consumption. Notably, the literature recognizes that while both power and status represent fundamental aspects of hierarchical differentiation, they are conceptually distinct (Dubois et al. 2012, 2015; Fiske et al. 2016). Power is defined as asymmetric control over resources or other people in social relationships, while status refers to respect and admiration in the eyes of others (Magee and Galinsky 2008).

\section{Power and green consumption}

Power can be manifested as a psychological state, a mindset, a dispositional trait or a situational factor (Anderson et al. 2012; Kifer et al. 2013). For example, varying levels of power exist and arise in different contexts such as in an organization (e.g., manager vs. subordinate), business negotiation (e.g., asymmetric supply and demand), consumption (e.g., ads and assortment options), and social stratification (e.g., social class) (Dubois et al. 2015; Fiske and Berdahl 2006; Keltner et al. 2003; Kraus et al. 2012). Thus, power is a relative concept and has transformative effects on consumer behaviors (for a review, see Rucker et al. 2012).

In particular, the agentic-communal model of power suggests that high power fosters an agentic orientation while low power fosters a communal orientation (Rucker et al. 2012). An agentic orientation leads people to be self-focused with a desire for independence and separation from others, whereas a communal orientation shifts people's attention to others with a desire for interdependence and connection with others (Abele and Wojciszke 2014; Rucker and Galinsky 2017). As a result, compared to having low power, having high power increases the focus on the self (Pitesa and Thau 2013), reduces perspective-taking (Galinsky et al. 2006), and lowers focus on others (Galinsky et al. 2008). Psychologically, high-power individuals feel more distant from 
others (Magee and Smith 2013). Moreover, having power motivates individuals to focus on gaining rewards and act in a self-interested and selfish manner (Dubois et al. 2015; Keltner et al. 2003). Consequently, they spend more on themselves than on others (Rucker et al. 2011). In contrast, low-power individuals feel that they have less control over others and the environment (Rucker and Galinsky 2008). They are more dependent and feel closer to others (Magee and Smith 2013; Rucker and Galinsky 2017). Thus, they are more attentive to others and spend more on others than on themselves (Dubois et al. 2015; Rucker et al. 2011).

Notably, green products are prosocial in nature, and buying green products incurs personal cost for the betterment of the society (Sexton and Sexton 2014). Thus, green purchase behavior requires individuals to sacrifice self-benefits for others (Griskevicius et al. 2010). As low power fosters greater endorsement of communal goals (e.g., helping others, serving the community; Rucker and Galinsky 2017), low-power consumers would show greater concern and generosity toward others, thus they are more willing to spend on green products for the benefit of society. In contrast, high power leads to greater endorsement of agentic goals (i.e., selfpromotion, self-interests), which impair such individuals' ability to consider others' interests, thus they tend to spend for the benefit of the self (Dubois et al. 2015; Galinsky et al. 2006). Taken together, we propose that a low-power state increases consumers' greater willingness to sacrifice self-interests for society, leading them to prefer green products over conventional alternatives compared to a high-power state. Formally, we hypothesize that:

H1: Consumers in a low-power state have greater preference for green (vs. conventional) products compared to those in a high-power state.

\section{The moderating role of GREEN values}

GREEN values refer to consumers' tendency to express the value of environmental 
protection through their purchase and consumption behaviors (Haws et al. 2014). It is part of a larger nomological network associated with conservation of not just environmental resources, but also personal financial, physical, and psychological resources. That is, GREEN values reflect consumers' integrated motives for resource protection at both environmental and personal levels (Cunningham et al. 2001). In developing a scale for GREEN values, Haws et al. (2014) empirically show that this construct is related to, yet distinct from, pro-environmental measures such as socially responsible purchase and disposal (Webb et al. 2008), connectedness to nature (Mayer and Frantz 2004), and ecologically conscious consumer behavior (Straughan and Roberts 1999). In particular, GREEN values can better predict consumer preference for green products compared to broader attitudes toward socially responsible behaviors or environmental consciousness (Haws et al. 2014). Recent research suggests that consumers high in GREEN values respond more favorably to green marketing communication efforts (Bailey et al. 2018). Notably, high GREEN values increase consumers' preference for green products through the motivated reasoning process, which enhances evaluations of non-green attributes of green products for those with high (vs. low) GREEN values (Haws et al. 2014). That is, only when consumers perceive greenness in themselves will they engage in motivated reasoning and behave in a value-consistent manner (Summers et al. 2016). We propose that when GREEN values are high, even though both high- and low-power consumers are more likely to engage in motivated reasoning, the extent to which they process the information differs. High power is associated with more abstract thinking — focusing on primary aspects of the stimulus, and extracting core information about the object (Smith and Trope 2006). Moreover, high power promotes focus on consumers' own internal desires and they become more attentive to utilitarian aspects of a product such as performance and quality (Rucker and Galinsky 2009). Thus, consumers in the high-power state would be less attentive to the non-green attributes of green products compared 
to those in the low-power state.

In contrast, when GREEN values are low, both low- and high-power consumers are less likely to engage in motivated reasoning for green products. Accordingly, we expect that the effect of power proposed in $\mathrm{H} 1$ is enhanced (vs. attenuated) among consumers who have high (vs. low) GREEN values. More formally:

H2: GREEN values moderate the effect of power on green consumption, such that:

H2a: When having high GREEN values, low-power consumers show greater preference for green products compared to high-power consumers.

H2b: When having low GREEN values, the preference for green products would not be significantly different between low- and high-power consumers.

\section{The moderating role of power distance belief}

Although power disparity exists in every society, individuals' attitudes toward power disparity vary (Hofstede 2001; Winterich and Zhang 2014), which has been found to differentially affect consumption behaviors (Gao et al. 2016; Han et al. 2017; Zhang et al. 2010). The extent to which people accept inequality in power and wealth (i.e., social and financial resources) is known as power distance belief (PDB; Hofstede 2001; Oyserman 2006). Power distance is conceptually distinct from power in that power reflects perceived control over valued resources (Magee and Galinsky 2008), whereas power distance pertains to the extent to which the individual expects and accepts inequality in power, regardless of the actual power (Winterich and Zhang 2014). Although PDB is traditionally assessed at the cultural or societal level, it can be manifested at the individual level within a specific society, or even within an organization (Farh et al. 2007; Winterich and Zhang 2014).

Prior research suggests that individuals' PDB can moderate the effect of power on 
prosocial behaviors (Han et al. 2017). Accordingly, we propose that PDB would moderate the effect of power on green consumption. Specifically, low-PDB individuals endorse social equality and believe that social hierarchy is nothing more than a convenient arrangement for social order (Han et al. 2017; Hofstede 2001; Oyserman 2006). In a low-PDB context, low-power individuals have little personal control over the environment and increased resource interdependence on others, thus leading to greater attention to others and orienting toward the social environment (Piff et al. 2010; Rucker et al. 2011, 2012). That is, low-power individuals are more communal and other-oriented than their high-power counterparts (Han et al. 2017). In contrast, high-power individuals are more self-focused, less dependent on others, and place more importance to selfbenefit than to others in their decision making (Han et al. 2017; Rucker et al. 2011; Rucker and Galinsky 2017). They are more agentic oriented than their lower-power counterparts (Rucker et al. 2012). Thus, low-power consumers are more likely to engage in green consumption than their high-power counterparts in the low-PDB context.

In the high-PDB context, social hierarchy is considered to be natural, legitimate, and inevitable (Farh et al. 2007; Hofstede 2001). High-PDB individuals endorse power disparity and believe that everyone should have a rightful place within the social order (Hofstede 2001). In such a context, individuals respect power inequality in social relationships, such that low-power individuals respect and obey their superiors and high-power individuals are to guide and protect their low-power subordinates (Rai and Fiske 2011). Accordingly, high-power individuals may feel morally obligated to support others who show them deference and respect (Han et al. 2017; Winterich and Zhang 2014). Indeed, as the inequality between high- and low-power individuals increases, high-power individuals are more sensitive to power asymmetries (Tost et al. 2015), which can induce feelings of stewardship and increase generosity toward others (Wade-Benzoni et al. 2008). Thus, in the high PDB context, high-power individuals have been found to donate 
more than their low-power counterparts (Han et al. 2017).

Although low-power individuals in the high-PDB context-like their counterparts in the low-PDB context —also depend on others for valuable resources, the wide disparities in power in the high-PDB context intensify their feeling of being resource constrained (Han et al. 2017); this feeling of resource scarcity shifts their focus to their own needs for survival (Roux et al. 2015). Thus, in the high-PDB context, high-power individuals would show greater preference for green products compared to their low-power counterparts. Taken together, we hypothesize that:

H3: Power distance belief moderates the effect of power on green consumption, such that:

H3a: In the high-PDB context, high-power consumers show greater preference for green products compared to their low-power counterparts.

H3b: In the low-PDB context, low-power consumers show greater preference for green products compared to their high-power counterparts.

We conducted four experimental studies to test our hypotheses. Studies 1a and $1 \mathrm{~b}$ examined the main effect of power using complementary designs across both adult and student samples. Study 2 confirmed the main effect using a more stringent design by introducing a control condition, and tested the moderating effect of GREEN values. Study 3 replicated the main effect using a different product category, and examined the moderating effect of PDB. The overall conceptual framework and sequence of studies are depicted in Figure 1.

[Insert Figure 1 about here]

\section{Study 1}

Study 1 tested the main effect that low-power consumers have greater preference for green (vs. conventional) products compared to high-power consumers (H1). We designed Studies 1a and 1b to be complementary. Specifically, Study 1a used a within-participant design 
by asking participants to indicate their preference between green and conventional products. To eliminate the potential carryover effect, Study $1 \mathrm{~b}$ used a between-participants design for the green and conventional products. In addition, we used two different methods to manipulate power; Study 1a used a recall task to prime power (Rucker and Galinsky 2008) while Study 1b used a role-play task to prime power (Rucker et al. 2011). To increase generalizability of the effect among different populations, Study 1a was conducted using an adult sample while Study 1b was conducted using a student sample.

\section{Study 1a}

\section{Design and participants}

Study la used a one factor two-level (power: high vs. low) between-participants design. The dependent variable was consumers' preference for the green product over the conventional product. We recruited 156 participants (44.20\% female, $M_{\text {age }}=34.57$ years) on Amazon's MTurk who received financial compensation. Prior research indicates that M-Turk can be used to obtain inexpensive yet high quality data (Goodman and Paolacci 2017). Moreover, M-Turk participants can respond to experimental stimuli in ways similar to participants in research labs (Berinsky, Huber, and Lenz 2012). Most participants had an associate degree or higher (77.56\%) and reported an annual household income above $\$ 40,000(62.82 \%)$.

\section{Procedure and measures}

Participants first completed a "memory test," which was actually the episodic recall task to prime power (Rucker and Galinsky 2008). Specifically, participants were asked to recall and write down a particular incident in which they had power over another individual (high-power condition), or someone else had power over them (low-power condition). As a manipulation 
check, participants reported how powerful they felt on three items $(1=$ not powerful at all / not at all in control / not influential at all, 7 = very powerful / in complete control / completely influential $)$, forming an index of power as a manipulation $\operatorname{check}(M=3.94, \mathrm{SD}=1.65, \alpha=.93)$.

Following that, participants were exposed to two advertisements for batteries adopted from Griskevicius et al. (2010), with one labeled as "Product A" (conventional condition) and the other labeled as "Product B" (green condition). The two products were specified with the same price. Participants indicated their product preference ("Which of these two batteries is more attractive to you?" $1=$ definitely product $A, 9=$ definitely product $B ; M=5.79, \mathrm{SD}=2.54)$. In addition, the effects of power on green consumption could potentially be confounded by status motives (Griskevicius et al. 2010). Accordingly, we measured need for status as a covariate. Sample items included, "I have a desire to increase my position in the social hierarchy," and "I want to improve my social standing as compared to others" $(1=$ definitely false, $7=$ definitely true; $M=3.60, \mathrm{SD}=1.70, \alpha=.97)$. As upward comparison by the lower class could result in a negative mood that might increase their desire for communal feelings, we measured mood as a control variable $(1=$ very sad / very depressed / very negative, $7=$ very happy / very cheerful / very positive; $M=4.82, \mathrm{SD}=1.21, \alpha=.94$ ), followed by their demographics.

\section{Results and discussion}

Manipulation checks. An ANOVA on the power index showed that participants in the high-power condition felt more powerful than those in the low-power condition $\left(M_{\text {high }}=4.75, \mathrm{SD}\right.$ $=1.40$ vs. $\left.M_{\text {low }}=3.11, \mathrm{SD}=1.47 ; F(1,154)=50.21, p<.001, \eta_{\mathrm{p}}^{2}=.246\right)$. In addition, the manipulation of power did not influence either $\operatorname{mood}\left(M_{\mathrm{high}}=4.76, \mathrm{SD}=1.25\right.$ vs. $M_{\text {low }}=4.88$, $\left.\mathrm{SD}=1.17 ; F(1,154)=.43, p=.51, \eta_{\mathrm{p}}^{2}=.003\right)$ or need for status $\left(M_{\mathrm{high}}=3.40, \mathrm{SD}=1.74\right.$ vs. $\left.M_{\text {low }}=3.80, \mathrm{SD}=1.65 ; F(1,154)=2.14, p=.15, \eta_{\mathrm{p}}{ }^{2}=.014\right)$. Thus, the manipulation of power 
was successful, and not confounded with mood or status motives.

Product preference. ANOVA results on product preference showed a significant effect of power $\left(F(1,154)=4.54, p=.035, \eta_{\mathrm{p}}^{2}=.029\right)$, such that the participants in the low-power condition $\left(M_{\mathrm{low}}=6.22, \mathrm{SD}=2.32\right)$ had significantly greater preference for the green battery than those in the high-power condition $\left(M_{\text {high }}=5.36, \mathrm{SD}=2.69\right)$, supporting H1. ANCOVA with covariates (age, gender, income, education, mood, and need for status) did not change the results for the main effect of power $\left(F(1,148)=4.32, p=.039, \eta_{\mathrm{p}}{ }^{2}=.028\right)$. Among the covariates, only gender had a marginally positive effect, in that female participants had greater preference for the green battery compared to their male counterparts $\left(F(1,148)=3.54, p=.062, \eta_{\mathrm{p}}^{2}=.023\right)$.

Results of Study 1a provided initial evidence supporting H1, in that individuals in a lowpower state had greater preference for the green product over the conventional product compared to those in a high-power state.

\section{Study 1b}

Study $1 \mathrm{~b}$ aimed to replicate the main effect of power on green consumption using different product stimuli and a different sample to increase the robustness of the results.

\section{Design and participants}

Study $1 \mathrm{~b}$ used a 2 (power: high vs. low) $\times 2$ (product greenness: green vs. conventional) between-participants design. We recruited 219 undergraduate students $\left(66.20 \%\right.$ female, $M_{\text {age }}=$ 20.01 years) from a major university in exchange for partial course credit.

\section{Procedure and measures}

We first manipulated power using a role-play method from the literature (Rucker et al. 
2011). In the high-power condition, participants were asked to play the role of a manager, who supervises and makes decisions that would affect their subordinates; whereas in the low-power condition, participants were assigned to the role of a subordinate, who has to follow orders from the manager and be evaluated by the manager. After that, participants rated how powerful they felt on three items as in Study 1a, forming an index of power for manipulation check $(M=4.36$, $\mathrm{SD}=1.76, \alpha=.93)$.

Next, participants read a shopping scenario for a hand wash (see Appendix). The images of the hand wash in both green and conventional conditions were identical except that in the green condition, the product was labeled as "eco-friendly formula," while in the conventional condition, the product was labeled as "fact-acting formula." Following that, participants rated how likely, how inclined and how willing they were to buy the product $(1=$ not at all, $7=$ very much; Peloza et al. 2013). The three items were averaged to form an index of purchase intention $(M=4.05, \mathrm{SD}=1.04, \alpha=.85)$.

As a manipulation check, they rated product greenness on three items from Lin and Chang (2012) (1 = not at all environmentally friendly / not at all green product / very harmful to the environment; 7 = very environmentally friendly / very green product / very beneficial to the environment $M=4.46, \mathrm{SD}=1.28, \alpha=.88)$. In addition, we measured perceived effectiveness $(1$ $=$ not at all effective, $7=$ very effective; $M=4.63, \mathrm{SD}=1.10)$ and quality $(1=$ very low quality, 7 $=$ very high quality; $M=4.37, \mathrm{SD}=1.03$ ) as relevant covariates. We also measured individual difference in environmental consciousness as a covariate using the 12-item NEP (New Environmental Paradigm) Scale (Lin and Chang 2012). Sample items included, "Humans are severely abusing the environment," and "Humans have the right to modify the natural environment (reversed-coded)" $(M=4.77, \mathrm{SD}=.66, \alpha=.70)$. Finally, participants reported their mood state as in Study 1a $(M=4.48, \mathrm{SD}=1.05, \alpha=.88)$ and demographics. 


\section{Results and discussion}

Manipulation checks. ANOVA results showed that participants in the high-power condition felt more powerful than those in the low-power condition $\left(M_{\text {high }}=5.62, \mathrm{SD}=1.09\right.$ vs. $\left.M_{\text {low }}=3.13, \mathrm{SD}=1.38 ; F(1,217)=218.58, p<.001, \eta_{\mathrm{p}}{ }^{2}=.502\right)$. In addition, the two conditions were not significantly different in reported $\operatorname{mood}\left(M_{\mathrm{high}}=4.50, \mathrm{SD}=1.04\right.$ vs. $M_{\mathrm{low}}=4.45, \mathrm{SD}=$ $\left.1.08 ; F(1,217)=.19, p=.68, \eta_{\mathrm{p}}^{2}=.001\right)$. Moreover, the hand wash in the green condition was perceived to be greener than the one in the conventional condition $\left(M_{\text {green }}=5.03, \mathrm{SD}=1.19 \mathrm{vs}\right.$. $\left.M_{\text {conventional }}=3.90, \mathrm{SD}=1.13 ; F(1,217)=51.48, p<.001, \eta_{\mathrm{p}}{ }^{2}=.192\right)$. The two products were not significantly different in their perceived quality and effectiveness (both $p s>.29$ ). Thus, the manipulations of power and product greenness were both successful.

Purchase intention. A 2 (power) $\times 2$ (product) ANOVA on purchase intention showed a significant interaction effect of power $\times$ product greenness $\left(F(1,215)=17.68, p<.001, \eta_{\mathrm{p}}{ }^{2}\right.$ $=.076)$ and a marginally significant effect of product greenness $\left(F(1,215)=3.50, p=.063, \eta_{\mathrm{p}}^{2}\right.$ $=.015)$. There were no other significant effects $(p>.21)$. Pairwise comparison (see Figure 2) showed that participants in the low-power condition had higher purchase intention for the green product than for the conventional product $\left(M_{\text {green }}=4.38, \mathrm{SD}=1.11 \mathrm{vs} . M_{\text {conventional }}=3.56, \mathrm{SD}\right.$ $\left.=.98, F(1,215)=18.72, p<.001, \eta_{\mathrm{p}}^{2}=.08\right)$; while participants in the high-power condition showed no significant difference in their purchase intentions for the two products $\left(M_{\text {green }}=3.98\right.$, $\mathrm{SD}=.99$ vs. $\left.M_{\text {conventional }}=4.30, \mathrm{SD}=.91, F(1,215)=2.68, p>.10, \eta_{\mathrm{p}}{ }^{2}=.012\right)$. ANCOVA with mood, perceived quality, performance, and environmental consciousness ${ }^{1}$ as covariates did not change the results for the interaction effect of power $\times$ product greenness $(F(1,211)=13.52, p$

\footnotetext{
${ }^{1}$ Following a reviewer's suggestion, we tested the interaction effect of power and environmental consciousness (NEP scale) on purchase intention. Results showed that the interaction effect was not significant $(b=-.18, p=.27)$.
} 
$\left.<.001, \eta_{\mathrm{p}}^{2}=.06\right)$

[Insert Figure 2 about here]

Viewed another way, for the green product, participants in the low-power condition had higher purchase intention than those in the high-power condition $\left(M_{\text {low }}=4.38\right.$ vs. $M_{\text {high }}=3.98$, $\left.F(1,215)=15.06, p<.001, \eta_{\mathrm{p}}^{2}=.065\right)$. Conversely, for the conventional product, participants in the high-power condition had higher purchase intention than those in the low-power condition $\left(M_{\text {low }}=3.56\right.$ vs. $\left.M_{\text {high }}=4.30, F(1,215)=4.32, p=.039, \eta_{\mathrm{p}}^{2}=.02\right)$. Thus, H1 was supported.

Across Studies 1a and 1b, we found that participants in the low-power state had greater propensity for green consumption than those in the high-power state. Although price was an important consideration when buying green products and had a significant effect on propensity for green consumption, both studies showed that the effect of power was independent of the effect of price. Moreover, we found that the effect of power on green consumption still held after controlling for general environmental consciousness. This implies that power could predict green consumption even after considering the variance in general environmental consciousness.

\section{Study 2}

Having shown the main effect of power in Studies 1a and 1b, Study 2 had three objectives. First, it was unclear from Studies $1 \mathrm{a}$ and $1 \mathrm{~b}$ whether the propensity for green consumption was driven by an increase in low power or a decrease in high power, relative to the baseline. Thus, we added a control condition for more insights. Second, we explicitly specified the same price in both green and conventional product conditions to eliminate the potential effects of price on green purchase behavior. Third, we wanted to examine the moderating effect of GREEN values (H2). At the same time, as there could be potential overlaps between GREEN values and environmental consciousness, we also tested for the moderating effect of 
environmental consciousness.

\section{Design and participants}

Study 2 used a one factor three-level (power: high vs. control vs. low) betweenparticipants design. The dependent variable was consumers' preference for the green product over the conventional product. We measured GREEN values as a continuous variable. We recruited 275 participants ( $57.82 \%$ female, $M_{\text {age }}=35.85$ years) on Turkprime who received financial compensation. Most participants had an associate degree or higher (72.73\%), and an annual household income above $\$ 40,000(69.09 \%)$.

\section{Procedure and measures}

As in Study 1a, participants first completed a "memory test" to prime low versus high power (Rucker and Galinsky 2008). The control condition required participants to recall and write about a regular trip to a grocery store. As a manipulation check, participants reported how powerful they felt on three items as in Study 1a $(M=4.38 \mathrm{SD}=1.56, \alpha=.89)$.

Next, participants were directed to an ostensibly unrelated study on product evaluation. They read that, "A company manufactures bag products such as suitcases, handbags, and backpacks. Recently, the research team has been developing two new backpacks. Before launching them in the market, the company would like to get feedback from customers on the new products." Then they saw two versions of a backpack side-by-side with the same price (Griskevicius et al. 2010), with one labeled as "Product A" (green condition) and the other labeled as "Product B" (conventional condition). Participants indicated their product preference on a 9-point scale ("Which of these two products is more attractive to you?" $1=$ definitely product $A, 9=$ definitely product $B$ ). The score was reverse-coded, such that a higher score 
indicated greater preference for the green backpack $(M=3.87, \mathrm{SD}=2.88)$.

As a manipulation check, participants rated the greenness of each product using two items from Lin and Chang (2012), "The backpack is a green product," and "The backpack is an environmentally-friendly product" $\left(M_{\text {green }}=6.45, \mathrm{SD}=.97, \mathrm{r}=.80 ; M_{\text {conventional }}=3.14, \mathrm{SD}=1.33\right.$, $\mathrm{r}=.84)$. Following that, we measured consumers' green consumption values using the GREEN scale (Haws et al. 2014). Sample items included, "It is important to me that the products I use do not harm the environment," and "I consider the potential environmental impact of my actions when making many of my decisions" ( 1 = strongly disagree, 7 = strongly agree $)$. The six items were averaged to form an index of GREEN values, with higher scores reflecting greater intrinsic green values $(M=4.61, \mathrm{SD}=1.22, \alpha=.93)$.

In addition, as in Studies 1a and 1b, we measured need for status (Dubois et al. 2012; $M=$ 3.83, $\mathrm{SD}=1.73, \alpha=.96$ ), environmental consciousness using the NEP scale (Lin and Chang $2012 ; M=5.05, \mathrm{SD}=.98, \alpha=.87)$, and $\operatorname{mood}(M=5.07, \mathrm{SD}=1.28, \alpha=.93)$ as relevant covariates. Finally, participants reported their demographics.

\section{Results and discussion}

Manipulation checks. An ANOVA on the power index showed that the three conditions were significantly different in the reported feelings of power $\left(F(2,272)=14.92, p<.001, \eta_{\mathrm{p}}{ }^{2}\right.$ $=.099)$, such that participants in the high-power condition felt more powerful $\left(M_{\text {high }}=5.00, \mathrm{SD}=\right.$ $1.30)$ than those in the low-power $\left(M_{\text {low }}=3.75, \mathrm{SD}=1.84\right)$ and control conditions $\left(M_{\text {control }}=\right.$ 4.41, $\mathrm{SD}=1.27$, all $p s<.01)$. As in Study 1a, the manipulation of power did not influence either $\operatorname{mood}\left(M_{\text {high }}=5.08, \mathrm{SD}=1.18\right.$ vs. $M_{\text {control }}=5.09, \mathrm{SD}=1.23$ vs. $M_{\text {low }}=5.06, \mathrm{SD}=1.42 ; F(2$, $\left.272)=.02, p=.98, \eta_{\mathrm{p}}^{2}=.000\right)$ or need for status $\left(M_{\text {high }}=3.99, \mathrm{SD}=1.61\right.$ vs. $M_{\text {control }}=3.73, \mathrm{SD}$ $=1.89$ vs. $\left.M_{\mathrm{low}}=3.78, \mathrm{SD}=1.66 ; F(2,272)=.58, p=.55, \eta_{\mathrm{p}}^{2}=.004\right)$. 
In addition, participants rated Product A to be greener than Product B $\left(M_{\text {green }}=6.45, \mathrm{SD}\right.$ $=1.97$ vs. $\left.M_{\text {conventional }}=3.14, \mathrm{SD}=1.32 ; t(274)=30.65, p<.001\right)$. Moreover, the manipulation of power also did not influence the reported GREEN values $(F(2,272)=.36, p=.69)$, which enabled us to conduct the moderation analysis. Thus, the manipulations of power and product greenness were successful.

Product preference. An ANOVA on product preference revealed a significant effect of power $\left(F(2,272)=3.64, p=.027, \eta_{\mathrm{p}}^{2}=.03\right)$, such that participants in the low-power condition $\left(M_{\text {low }}=4.53, \mathrm{SD}=3.00\right)$ had higher preference for the green backpack than those in the control $\left(M_{\text {control }}=3.49, \mathrm{SD}=2.78, p=.014\right)$ and high-power conditions $\left(M_{\text {high }}=3.60, \mathrm{SD}=2.70, p\right.$ $=.031)$. Moreover, participants in the high-power and control conditions did not show significant difference in their preference for the green backpack $(p=.79)$. ANCOVA with mood, need for status, and environmental consciousness as covariates did not change the conclusion for the main effect of power $\left(F(2,269)=5.31, p=.005, \eta_{\mathrm{p}}^{2}=.04\right)$. Thus, H1 was further confirmed.

Moderating effect of GREEN values. A moderated hierarchical regression analysis was performed to test the moderating effect of GREEN values. As power was primed at three levels, we created two dummy variables with the low-power condition as the reference group (D1: low power $=0$, high power $=0$, control $=1$; D2: low power $=0$, high power $=1$, control $=0$ ). Following Aiken and West (1991), we mean-centered GREEN values and created two interaction terms with D1 and D2 (D1 × GREEN, D2 × GREEN).

As shown in Table 1, Model 1 was the baseline model with only demographic variables. There was a marginally significant effect of gender $(\beta=.11, p=.085)$, such that female participants had slightly greater preference for the green backpack than their male counterparts. Nonetheless, overall Model 1 was not significant $(F(4,270)=1.56, p=.18)$. Model 2 showed the significant main effects of D1 $(\beta=-.17, p=.014)$ and D2 $(\beta=-.15, p=.031)$ after 
accounting for the control variables. Overall, Model 2 was significant $(F(6,268)=2.26, p$ $=.038$ ). Finally, the explanatory power of Model 3 was significantly improved after including GREEN values and their interactions with power $(F(9,265)=22.08, p<.001)$. Specifically, there were significant interaction effects of D1 $\times$ GREEN $(\beta=-.24, p=.001)$ and D2 $\times$ GREEN ( $\beta=-.17, p=.012)$, in addition to the significant main effects of $\mathrm{D} 1(\beta=-.13, p=.012)$, $\mathrm{D} 2$ ( $\beta=$ $-.14, p=.012)$, and GREEN values $(\beta=.85, p<.001)$. The positive and significant effect of GREEN values on green product preference was consistent with the literature (Haws et al. 2014).

[Insert Table 1 about here]

We plotted the interaction effects as shown in Figure 3. At high GREEN values (+1 SD), participants in the low-power condition had significantly higher preference for the green backpack compared to those in the high-power $\left(M_{\mathrm{low}}=6.81\right.$ vs. $M_{\mathrm{high}}=5.10, \mathrm{~b}=-1.71, t=-3.57$, $p<.001)$ and control conditions $\left(M_{\text {low }}=6.81\right.$ vs. $\left.M_{\text {control }}=4.97, \mathrm{~b}=-1.83, t=-3.90, p<.001\right)$, supporting H2a; whilst at low GREEN values (-1 SD), participants' preferences for the green backpack in the three conditions were not significantly different (all $p s>.60$ ), supporting H2b. We further conducted a floodlight analysis (Spiller et al. 2013) to identify the range of GREEN values at which the effect of power was significant. Results showed that participants in the lowpower condition had significantly higher preference for the green backpack than those in the high-power condition when the GREEN values score was at or above 4.37, $\mathrm{t}=-1.97, p=.05$, $\mathrm{LLCI}=-.6889, \mathrm{ULCI}=.0000$. Taken together, these results supported $\mathrm{H} 2$.

[Insert Figure 3 about here]

In addition, as environmental consciousness ${ }^{2}$ was related to GREEN values $(r=.42)$ and

\footnotetext{
${ }^{2}$ Following a reviewer's suggestion, we tested for discriminant validity between environmental consciousness (NEP scale) and GREEN values by conducting an exploratory factor analysis (EFA) and calculating the average variance extracted (AVE) for both constructs. Results showed that while GREEN values $(\alpha=.93)$ and NEP $(\alpha=.87)$ were moderately correlated $(\mathrm{r}=.42)$, the AVE of GREEN values (AVE $=.71)$ and NEP $(\mathrm{AVE}=.40)$ exceeded their shared variance (squared correlation $=.178$ ), indicating that the two constructs were distinct.
} 
preference for green backpack $(r=.27)$, we conducted another moderated regression analysis to test the potential moderating effect of environmental consciousness. Specifically, the model included the control variables (age, gender, education, and income), the core predictors (D1, D2, GREEN values, and NEP), as well as their interactions (D1 × GREEN, D2 × GREEN, D1 × $\mathrm{NEP}, \mathrm{D} 2 \times \mathrm{NEP})$. As expected, results showed the main effects of D1 $(\beta=-.14, p=.015), \mathrm{D} 2(\beta$ $=-.13, p=.016)$ and GREEN values $(\beta=.89, p<.001)$, as well as the significant interaction effects of D1 $\times \operatorname{GREEN}(\beta=-.28, p=.001)$ and $\mathrm{D} 2 \times \operatorname{GREEN}(\beta=-.21, p=.008)$. Neither the main effect of $\operatorname{NEP}(\beta=-.07, p=.42)$ nor their interactions $(\mathrm{D} 1 \times \mathrm{NEP}: \beta=.06, p=.425, \mathrm{D} 2 \times$ NEP: $\beta=.07, p=.326$ ) were significant. These results indicated that the GREEN values scale could better predict green product preference compared to broader attitudes toward socially responsible behaviors (i.e., environmental consciousness), consistent with the findings by Haws et al. (2014).

Taken together, Study 2 confirmed the effects of power on green consumption, such that having low power (vs. high power) led to greater preference for the green product $(\mathrm{H} 1)$. Moreover, compared to the control condition, we found it was low power that increased preference for the green product rather than high power that lowered preference for the green product. Importantly, these effects were salient among consumers with high GREEN values but weakened among consumers with low GREEN values $(\mathrm{H} 2)$, even after controlling for status motives, environmental consciousness, mood, and demographics. Another way of viewing this result is, for consumers with high GREEN values, their propensity for green consumption was higher when they were in a low-power state than in a high-power state. These findings have important implications on closing the attitude-behavior gap, as elaborated in the general discussion section. 


\section{Study 3}

Study 3 examined the moderating effect of the cultural variable power distance belief (PDB) in the relationship between power and green consumption (H3). We expected that a lowpower state would drive green consumption in the low-PDB context while a high-power state would drive green consumption in the high-PDB context. Notably, individual-level PDB can produce consistent effects as cultural-level PDB, and can be activated through priming methods (Winterich and Zhang 2014). Thus, we primed individual-level PDB following the procedure from prior research (Gao et al. 2016; Han et al. 2017).

\section{Design and participants}

Study 3 used a 2 (power: high vs. low) $\times 2$ (PDB: high vs. low) $\times 2$ (product greenness: green vs. conventional) between-participants design. We recruited 208 participants $(42.20 \%$ female, $M_{\text {age }}=35.53$ years) from Amazon's M-Turk who received financial compensation. Most participants had an associate degree or higher (75.00\%) and reported an annual household income above $\$ 40,000(61.06 \%)$.

\section{Procedure and measures}

On the cover page, participants read that they were going to complete three unrelated tasks. The first task was a sentence unscrambling exercise, which served to prime PDB (Han et al. 2017; Zhang et al. 2010). Specifically, participants were asked to form 10 meaningful sentences from 10 sets of scrambled words to do with social hierarchy (high PDB) or equality (low PDB). Upon completion, participants responded to three items for manipulation check: "For the time being, I am mainly thinking that," "At this moment, I feel that," and "On top of my mind right now are thoughts in agreement with saying" $(1=$ social equality is important, $7=$ 
social hierarchy is important). The three items were averaged to form a PDB index, with a higher score indicating a higher $\operatorname{PDB}(M=2.75, \mathrm{SD}=1.71, \alpha=.96)$.

The second task was a role-play task to prime power as in Study 1b (Rucker et al. 2011). As a manipulation check, participants indicated how powerful they felt using the same measures $(M=3.86, \mathrm{SD}=1.75, \alpha=.94)$.

Following that, participants transitioned to an ostensibly unrelated "third study," a shopping scenario for an all-purpose cleaner (see Appendix). They were randomly exposed to either the green or conventional version of the cleaner adapted from Haws et al. (2014). Specifically, in the green condition, the product was described as "formulated to be very environmentally friendly," and in the conventional condition, it was described as "very similar to other all-purpose cleaners available in the store." The remaining text was identical across the two product conditions. Participants indicated their purchase intention for the cleaner using the same items as in Study $1 \mathrm{~b}(M=4.59, \mathrm{SD}=1.23, \alpha=.93)$. We also asked them to indicate their willingness to pay for the cleaner ("How much are you willing to pay for this new cleaner? As a reference, the regular price for the product is $\$ 3.50$ in your local area." $M=3.52, \mathrm{SD}=.87$ ).

In addition, we measured perceived price $(1=$ not at all expensive, $7=$ very expensive; $M$ $=4.07, \mathrm{SD}=1.23)$, and product familiarity $(1=$ not familiar at all $/$ never seen it before, $7=$ very familiar / have seen it frequently; $M=2.63, \mathrm{SD}=1.76 ; \mathrm{r}=.91$ ) as control variables. As a manipulation check, participants rated product greenness on the same items as in Study $1 \mathrm{~b}(M=$ $4.66, \mathrm{SD}=1.35, \alpha=.93)$. Finally, participants reported their demographic details.

\section{Results and discussion}

Manipulation checks. A $2 \times 2$ MANOVA on the power and PDB indices revealed the main effect of power manipulation on the power index $\left(M_{\text {high-power }}=5.02, \mathrm{SD}=1.39\right.$ vs. $M_{\text {low- }}$ 
power $\left.=2.81, \mathrm{SD}=1.33 ; F(1,204)=134.30, p<.001, \eta_{\mathrm{p}}{ }^{2}=.397\right)$, and the main effect of PDB manipulation on the PDB index $\left(M_{\text {high-PDB }}=3.26, \mathrm{SD}=1.87\right.$ vs. $M_{\text {low-PDB }}=2.22, \mathrm{SD}=1.32 ; F(1$, 204) $\left.=20.59, p<.001, \eta_{\mathrm{p}}{ }^{2}=.092\right)$. There were no other significant effects $(p s>.40)$.

Moreover, an ANOVA on the product greenness index showed that the cleaner in the green condition was perceived to be greener than the one in the conventional condition ( $M_{\text {green }}=$ $5.46, \mathrm{SD}=.99$ vs. $\left.M_{\text {conventional }}=3.84, \mathrm{SD}=1.17 ; F(1,206)=116.9, p<.001, \eta_{\mathrm{p}}{ }^{2}=.362\right)$. There were no significant differences in perceived price $\left(F(1,206)=1.23, p=.29, \eta_{\mathrm{p}}{ }^{2}=.005\right)$ and product familiarity $\left(F(1,206)=.02, p=.88, \eta_{\mathrm{p}}{ }^{2}=.000\right)$ between the green and conventional product conditions. Thus, our manipulations of power, $\mathrm{PDB}$, and product greenness were successful as intended.

Purchase intention. A 2 (power) $\times 2(\mathrm{PDB}) \times 2$ (greenness) ANOVA on purchase intention revealed the significant effect of product greenness $\left(F(1,200)=17.18, p=.001, \eta_{\mathrm{p}}^{2}\right.$ $=.079)$, and the significant three-way interaction effect of power $\times \mathrm{PDB} \times$ greenness $(F(1,200)$ $\left.=32.52, p<.001, \eta_{\mathrm{p}}^{2}=.14\right)$. There were no other significant effects $(p \mathrm{~s}>.20)$.

We decomposed the three-way interaction effect as shown in Figure 4a. As predicted, in the low-PDB condition, low-power participants had higher purchase intention for the green cleaner than for the conventional one $\left(M_{\text {green }}=5.28, \mathrm{SD}=1.02\right.$ vs. $M_{\text {conventional }}=3.83, \mathrm{SD}=1.18$; $\left.F(1,99)=23.66, p<.001, \eta_{\mathrm{p}}^{2}=.19\right)$, while high-power participants did not show a significant difference in their purchase intentions for the two cleaners $\left(M_{\text {green }}=4.52, \mathrm{SD}=1.32\right.$ vs. $\left.M_{\text {conventional }}=4.93, \mathrm{SD}=.79 ; F(1,99)=1.61, p=.21, \eta_{\mathrm{p}}^{2}=.016\right)$. In contrast, in the high-PDB condition, high-power participants reported higher purchase intention for the green cleaner than for the conventional one $\left(M_{\text {green }}=5.21, \mathrm{SD}=.88\right.$ vs. $M_{\text {conventional }}=3.61, \mathrm{SD}=1.24 ; F(1,101)=$ $25.79, p<.001, \eta_{\mathrm{p}}{ }^{2}=.203$ ), while low-power participants did not show a significant difference in their purchase intention for the green and conventional cleaners $\left(M_{\text {green }}=4.58, \mathrm{SD}=.78\right.$ vs 
$\left.M_{\text {conventional }}=4.68, \mathrm{SD}=1.41 ; F<.10, p=.80, \eta_{\mathrm{p}}{ }^{2}=.001\right)$. These results supported $\mathrm{H} 3$.

Willingness to pay $(W T P)$. Similarly, a 2 (power) $\times 2(\mathrm{PDB}) \times 2$ (greenness) ANOVA on WTP revealed a significant main effect of product greenness $\left(F(1,200)=5.52, p=.020, \eta_{\mathrm{p}}{ }^{2}\right.$ $=.027)$ and a significant three-way interaction effect of power $\times \operatorname{PDB} \times$ greenness $(F(1,200)=$ $\left.20.72, p<.001, \eta_{\mathrm{p}}^{2}=.094\right)$ on WTP. There were no other significant effects $(p s>.37)$.

We decomposed the three-way interaction as shown in Figure 4b. As predicted, in the low-PDB condition, low-power participants had a higher WTP for the green cleaner than for the conventional one $\left(M_{\text {green }}=3.93, \mathrm{SD}=.73\right.$ vs. $M_{\text {conventional }}=3.26, \mathrm{SD}=.81 ; F(1,99)=9.75, p$ $=.002, \eta_{\mathrm{p}}{ }^{2}=.09$ ); while high-power participants did not show a significant difference in their WTP for the green and conventional cleaners $\left(M_{\text {green }}=3.65, \mathrm{SD}=.49\right.$ vs. $M_{\text {conventional }}=3.34, \mathrm{SD}$ $\left.=1.00 ; F(1,99)=2.00, p=.16, \eta_{\mathrm{p}}^{2}=.02\right)$. In contrast, in the high-PDB condition, high-power participants had a higher WTP for the green cleaner than for the conventional one ( $M_{\text {green }}=3.92$, $\mathrm{SD}=.73$ vs. $\left.M_{\text {conventional }}=2.98, \mathrm{SD}=.99 ; F(1,101)=14.46, p<.001, \eta_{\mathrm{p}}^{2}=.125\right)$, while lowpower participants did not show a significant difference in their WTP for the two cleaners $\left(M_{\text {green }}\right.$ $=3.41, \mathrm{SD}=.91$ vs. $\left.M_{\text {conventional }}=3.60, \mathrm{SD}=.88 ; F(1,101)<1, p=.43, \eta_{\mathrm{p}}{ }^{2}=.006\right)$. These results further supported $\mathrm{H} 3$.

[Insert Figures $4 \mathrm{a}$ and $4 \mathrm{~b}$ about here]

Taken together, Study 3 showed the moderating effect of PDB in the relationship between power and green consumption as evidenced by participants' purchase intention and willingness to pay. As predicted, low-power consumers drove green consumption in the lowPDB context, while high-power consumers drove green consumption in the high-PDB context. These results indicated that the cultural factor of PDB could moderate the effects of power on green consumption. 


\section{General Discussion and Conclusion}

The present research examines the effects of power on green consumption, revealing consumers' green consumption as a function of their psychological feeling of power. Across all four studies, we consistently find that low-power consumers have greater preference for green products over conventional products compared to high-power consumers. Importantly, we reveal that the effects of power on green consumption are moderated by two factors. First, the effect of low power on green consumption would be more salient among those having high GREEN values (Study 2). Moreover, we show that these effects are not confounded by consumers' need for status motives by controlling for this variable (Studies 1a and 2). Finally, we show that the cultural factor of PDB could also moderate the effects of power on green consumption, such that low power drives green consumption in the low-PDB context while high power drives green consumption in the high-PDB context (Study 3). By linking power to green consumption, the present research yields novel insights that have significant theoretical and practical implications.

\section{Theoretical implications}

To the best of our knowledge, the present research is the first to examine the causality between power and green consumption. In this vein, we bridge the literature between power and green consumption, extending findings from prior research (Griskevicius et al. 2010; Olson 2013; Prothero et al. 2011; Rucker and Galinsky 2008). Specifically, prior research on power suggests that low-power individuals pursue status consumption to compensate for being powerless (Rucker and Galinsky 2008), while the green literature shows that status motives could promote green consumption (Griskevicius et al. 2010). Our findings show that power can influence green consumption without invoking the externally-conferred status motive to compensate for having low power. 
In this vein, we contribute to the literature on the paradox of "going green to be seen." Our findings suggest that the effect of power could apply in an inconspicuous consumption context, in contrast to status motives in conspicuous green consumption (Griskevicius et al. 2010). Our approach addresses the concern that status motive leads to superficial rather than intrinsic green consumption behaviors (Van der Wal et al. 2016). Specifically, we disentangle the effects of power from status in several ways.

First, in our experiments we avoided using conspicuous consumption products as our stimuli. Rather, we chose battery, hand wash, backpack, and cleaner as our stimuli, which are common everyday products. In selecting such inconspicuous products, we minimized the influence of status motives. Second, to address the potential confounding effect of status motives in green consumption, we measured and controlled for need for status in our studies. We showed that our predicted effects of power on green consumption held after controlling for need for status (Studies 1a and 2). These findings suggest that the effects of power (based on resources) and status (based on prestige) are distinct in the green consumption context (Deng et al. 2018; Fiske et al. 2016).

Meanwhile, our key finding on the effects of power suggests that the communal orientation embedded in low power leads to greater propensity for green consumption compared to the agentic orientation embedded in high power. This is consistent with prior literature suggesting that cultivating communal feelings can promote consumers' behavioral change for green products (Romani et al. 2016).

Importantly, we identify two boundary conditions for the effects of power on green consumption, which provide a deeper understanding on value-consistent motivators. First, we show that low-power consumers' propensity for green consumption is more salient among those with high green consumption values. This finding potentially can help close the attitude-behavior 
gap. That is, to mobilize high GREEN-value consumers to act in a value-consistent manner, priming them with a low power state rather than empowering them would be more effective. In addition, by linking power to GREEN values, we address calls for research to examine the personal well-being of consumers as well as the collective benefits for the environment (Haws et al. 2014; Sheth et al. 2011; Weber 2015; Zaval et al. 2015). Exploring the interaction effects of GREEN values and power, which relate to consumers' personal resources, provide more nuanced predictions for green consumption (Haws et al. 2014). Prior research indicates that the activation of green-related concepts in consumers' decision-making process is critical to promoting valueconsistent behaviors (Bailey et al. 2018; Haws et al. 2014; Weber 2015). Our findings extend this line of research by revealing the interaction effects power and GREEN values on green consumption. At the same time, we rule out the competing moderating effect of environmental consciousness.

Finally, we demonstrate that the differential effects of low versus high power on green consumption are also subject to consumers' cultural orientation, extending the literature on power distance belief (Gao et al. 2016; Han et al. 2017). While the cultural construct of power distance has long been operationalized at the societal level (Hofstede 2001), our approach shows that PDB can also be primed within individuals in a specific society (Gao et al. 2016). To this end, prior research offers suggestions on practical ways to prime PDB in marketing messages and ad appeals (Winterich and Zhang 2014), which have practical implications.

\section{Practical implications}

Policy makers recognize that individual and household consumption behaviors exert substantial impacts on the environment (European Commission 2012). One way to reduce consumers' environmental footprint is to encourage them to purchase green products 
(Griskevicius et al. 2010; Haws et al. 2014), especially products purchased on a regular basis (Barbarossa and De Pelsmacker 2016). In the long term, changing consumers' preference from conventional products to green alternatives might act as a gateway to other pro-environmental behaviors such as energy conservation (Sachdeva et al. 2015). In this vein, our findings suggest several novel ways to increase consumers' preference for green products: social power, GREEN values, and the cultural factor of PDB.

Our key finding is that consumers in a low-power state have greater propensity for green consumption compared to consumers in a high-power state, in particular for consumers having high GREEN values. As power can be manifested as a psychological state, a situational factor, as well as a dispositional trait (Keltner et al., 2003; Kifer et al., 2013), this implies that even individuals with a chronic sense of high power (e.g., as reflected by their personality, economic status, and position in society) can be primed to temporarily experience low power when making their decisions. To illustrate, retailers can manipulate contextual factors in the store (i.e., temperature and ambient scent; Madzharov et al. 2015) to prime power. For example, cool scents such as eucalyptus spearmint and peppermint can lower the sense of power (Madzharov et al. 2015). In addition, marketers can also influence consumers' sense of power through the message conveyed in brands and ads (Rucker et al. 2011). For example, marketers could prime low power using words or images related to power, such as "The natural environment is greater than any of us, if we don't take care of it, it will not be there for our future generation."

Second, consumers' intrinsic GREEN values have been shown to influence their responses to brands' marketing communication efforts advocating green consumption (Bailey et al. 2018). Thus, our findings on the interaction effects of GREEN values and power can help policy makers and marketers to design more effective marketing communication strategies. For example, policy makers should focus on cultivating GREEN values among low-power consumer 
segments (e.g., lower social class or income groups). By the same token, marketers could also prime consumers with high GREEN values to be in a low-power state to mobilize their green behavior, which potentially helps to close the attitude-behavior gap. Similarly, marketers of green products could emphasize how their goods help protect environmental resources; making GREEN values more salient at the individual level will have spillover effect at the environmental level. To illustrate, the fashion brand Alternative Apparel emphasizes that over $80 \%$ of their garments are made with sustainable materials and processes (Alternative Apparel 2018).

Finally, marketers and policy makers should understand and act on the cultural differences in green consumption. In particular, our findings suggest that empowering consumers as a means of promoting green consumption would be ineffective in a low-PDB culture (Thøgersen 2005). Rather, it would be more effective to prime a high sense of power to promote green consumption in a high-PDB society, and to prime a low sense of power in a low-PDB society. The literature offers suggestions on ways to influence consumers' PDB. For example, advertising messages may trigger high-PDB belief using slogans such as "For those who want to reach the top" (Lalwani and Forcum 2016) or low-PDB belief using slogans such as "Equality has no boundaries" (Wang et al. 2018).

\section{Future research directions}

Notwithstanding the novel findings, the present research has several limitations that merit further research attention. First, future research could replicate our research in a field environment to provide external validation for our findings. Second, the present research focuses on regularly purchased household products (i.e., battery, hand wash, backpack, and cleaner), and future research could examine high-involvement products (e.g., refrigerators and electric cars) to test the robustness of the findings. Third, as our focus in this research is the malleability of social 
power in promoting green consumption, we identify two important boundary conditions for the effects of power. Further research could explore the mechanisms underlying these effects.

For instance, long time horizons and social distance are viewed as key psychological barriers to pro-environmental action (Zaval et al. 2015). Thus, exploring the effects of power from a social distance perspective (Magee and Smith 2013) would be promising. In this vein, construal levels could be a potential mechanism that explains the effects of power in green consumption. Future research could explore this possibility for green product purchase and other sustainable behaviors such as recycling and energy conservation.

In addition, we show that the effect of power differs from that of status in the context of green consumption, consistent with prior research indicating that power and status are closely related but distinct concepts in the social hierarchy, reflecting resources and prestige, respectively (Magee and Galinsky 2008). Nonetheless, recent research suggests an interaction effect between status and power (Deng et al. 2018). Potentially some consumers may have both resources and prestige (e.g. the upper social class and celebrities), some may lack both (e.g., the lower social class and homeless), while others may have one but not the other, such as having power but lacking status (e.g., airport security). Notably, power is more of a property within an individual, while status is more of a property of observers (Magee and Galinsky 2008). Thus, it would be meaningful to explore the interaction effect of these two facets, or even extend to the domain of social class for more nuanced insights (Yan, Keh, and Chen 2019).

Finally, consistent with prior research (Torelli and Shavitt 2010; Zhong et al. 2006), we show that the effects of power vary by culture. Nonetheless, we explored only one dimension of culture (i.e., PDB), operationalized at the individual level. We recognize that individuals could construct and enact power differently in different societies. Thus, future research can explore the moderating effects of other dimensions of culture such as uncertainty avoidance and 
individualism vs. collectivism (Hofstede 2001). In particular, exploring the three-way interaction effects of power, power distance belief, and GREEN values on green consumption could generate new insights, particularly from a cross-cultural perspective. 


\section{Appendix: Product Stimuli for Studies $1 \mathrm{~b}$ and 3}

\section{Study 1b: Hand wash}

\begin{tabular}{|l|r|}
\hline Green Product Condition & Conventional Product Condition \\
\hline & \\
\hline & \\
\hline & \\
\hline
\end{tabular}

Study 3: All-purpose Cleaner (adapted from Haws, Winterich, and Naylor 2014)

\begin{tabular}{|l|l|}
\hline \multicolumn{1}{|c|}{ Green Product Condition } & \multicolumn{1}{|c|}{ Conventional Product } \\
\hline $\begin{array}{l}\text { This all-purpose cleaner can be sprayed on } \\
\text { counters, appliances, stainless steel, sinks, } \\
\text { and toilets. It is formulated to be very } \\
\text { environmentally friendly. }\end{array}$ & $\begin{array}{l}\text { This all-purpose cleaner can be sprayed on } \\
\text { counters, appliances, stainless steel, sinks, } \\
\text { and toilets. It is very similar to other all- } \\
\text { purpose cleaners available in the store. }\end{array}$ \\
\hline
\end{tabular}




\section{References}

Abele, A.E., \& Wojciszke, B. (2014). Communal and agentic content in social cognition: A dual perspective model. Advances in Experimental Social Psychology, 50(1), 198-255.

Aiken, L.S., \& West, S.G. (1991). Multiple regression: Testing and interpreting interactions. Newbury Park, CA: Sage.

Alternative Apparel (2018). Sustainability. https://www.alternativeapparel.com/socialresponsibility, accessed December 2, 2018.

Amatulli, C., De Angelis, M., Peluso, A.M., Soscia, I., \& Guido, G. (2019). The effect of negative message framing on green consumption: An investigation of the role of shame. Journal of Business Ethics, 157(4), 1111-1132.

Anderson, C., John, O.P., \& Keltner, D. (2012). The personal sense of power. Journal of Personality, 80(2), 313-344.

Antonetti, P., \& Maklan, S. (2014). Feelings that make a difference: How guilt and pride convince consumers of the effectiveness of sustainable consumption choices. Journal of Business Ethics, 124(1), 117-134.

Bailey, A.A., Mishra, A.S., \& Tiamiyu, M.F. (2018). Application of GREEN scale to understanding U.S. consumer response to green marketing communications. Psychology \& Marketing, 35(11), 863-875.

Barbarossa, C., \& De Pelsmacker, P. (2016). Positive and negative antecedents of purchasing eco-friendly products: A comparison between green and non-green consumers. Journal of Business Ethics, 134(2), 229-247.

Berinsky, A.J., Huber, G.A., \& Lenz, G.S. (2012). Evaluating online labor markets for experimental research: Amazon.com's Mechanical Turk. Political Analysis, 20(3), 351-368.

Brough, A.R., Wilkie, J.E., Ma, J., Isaac, M.S., \& Gal, D. (2016). Is eco-friendly unmanly? The 
green-feminine stereotype and its effect on sustainable consumption. Journal of Consumer Research, 43(4), 567-582.

Bullard, O., \& Manchanda, R.V. (2013). Do sustainable products make us prevention focused? Marketing Letters, 24(2), 177-189.

Carrington, M.J., Neville, B.A., \& Whitwell, G.J. (2010). Why ethical consumers don’t walk their talk: Towards a framework for understanding the gap between the ethical purchase intentions and actual buying behaviour of ethically minded consumers. Journal of Business Ethics, 97(1), 139-158.

Carrington, M.J., Neville, B.A., \& Whitwell, G.J. (2014). Lost in translation: Exploring the ethical consumer intention-behavior gap. Journal of Business Research, 67(1), 2759-2767.

Choi, S., \& Ng, A. (2011). Environmental and economic dimensions of sustainability and price effects on consumer responses. Journal of Business Ethics, 104(2), 269-282.

Cunningham, W.P., Saigo, B.W., \& Cunningham, M.A. (2001). Environmental science: A global concern (7th ed.). New York: McGraw-Hill.

Deng, M., Guinote, A., \& Cui, L. (2018). When low power meets status: Powerlessness triggers behavioral inhibition only under low status. Social Cognition, 36(1), 134-166

Diamantopoulos, A., Schlegelmilch, B.B., Sinkovics, R.R., \& Bohlen, G.M. (2003). Can sociodemographics still play a role in profiling green consumers? A review of the evidence and an empirical investigation. Journal of Business Research, 56(6), 465-480.

Dubois, D., Rucker, D.D., \& Galinsky, A.D. (2012). Super size me: Product size as a signal of status. Journal of Consumer Research, 38(6), 1047-1062.

Dubois, D., Rucker, D.D., \& Galinsky, A.D. (2015). Social class, power, and selfishness: When and why upper and lower class individuals behave unethically. Journal of Personality and Social Psychology, 108(3), 436-449. 
European Commission (2012). Policies to encourage sustainable consumption.

http://ec.europa.eu/environment/eussd/pdf/report_22082012.pdf, accessed June 16, 2018.

European Environment Agency (2012). Consumption and the environment.

http://www.eea.europa.eu/publications/consumption-and-the-environment-2012, accessed May 2, 2018.

Farh, J.L., Hackett, R.D., \& Liang, J. (2007). Individual-level cultural values as moderators of perceived organizational support-employee outcome relationships in China: Comparing the effects of power distance and traditionality. Academy of Management Journal, 50, 715-729.

Fiske, S.T., \& Berdahl, J. (2006). Social power. In A.W. Kruglanski, \& E.T. Higgins (eds.), Social Psychology: Handbook of Basic Principles, $2^{\text {nd }}$ edition (pp. 678-692). New York: Guilford.

Fiske, S.T., Dupree, C.H., Nicolas, G., \& Swencionis, J.K. (2016). Status, power, and intergroup relations: The personal is the societal. Current Opinion in Psychology, 11, 44-48.

Galinsky, A.D., Magee, J.C., Gruenfeld, D.H., Whitson, J.A., \& Liljenquist, K.A. (2008). Power reduces the press of the situation: Implications for creativity, conformity, and dissonance. Journal of Personality and Social Psychology, 95(6), 1450-1466.

Galinsky, A.D., Magee, J.C., Inesi, M.E., \& Gruenfeld, D.H. (2006). Power and perspectives not taken. Psychological Science, 17(12), 1068-1074.

Gao, H., Winterich, K.P., \& Zhang, Y. (2016). All that glitters is not gold: How others' status influences the effect of power distance belief on status consumption. Journal of Consumer Research, 43(2), 265-281.

Gifford, R. (2014). Environmental psychology matters. Annual Review of Psychology, 65, 541579.

Gleim, M.R., Smith, J.S., Andrews, D., \& Cronin, J.J. Jr. (2013). Against the green: A multi- 
method examination of the barriers to green consumption. Journal of Retailing, 89(1), 44-61.

Goodman, J. K., \& Paolacci, G. (2017). Crowdsourcing consumer research. Journal of Consumer Research, 44(1), 196-210.

Griskevicius, V., Tybur, J.M., \& Van den Bergh, B. (2010). Going green to be seen: Status, reputation, and conspicuous conservation. Journal of Personality and Social Psychology, 98(3), 392-402.

Han, D., Lalwani, A.K., \& Duhachek, A. (2017). Power distance belief, power, and charitable giving. Journal of Consumer Research, 44(1), 182-195.

Haws, K.L., Winterich, K.P., \& Naylor, R.W. (2014). Seeing the world through GREEN-tinted glasses: Green consumption values and responses to environmentally friendly products. Journal of Consumer Psychology, 24(3), 336-354.

Hofstede, G. (2001). Culture's consequences: Comparing values, behaviors, institutions, and organizations across nations. Thousand Oaks, CA: Sage.

Keltner, D., Gruenfeld, D.H., \& Anderson, C. (2003). Power, approach, and inhibition. Psychological Review, 110(2), 265-284.

Kidwell, B., Farmer, A. \& Hardesty, D.M. (2013). Getting liberals and conservatives to go green: Political ideology and congruent appeals. Journal of Consumer Research, 40(2), 350367.

Kifer, Y., Heller, D., Perunovic, W.Q.E., \& Galinsky, A.D. (2013). The good life of the powerful: The experience of power and authenticity enhances subjective well-being. Psychological Science, 24(3), 280-288.

Kraus, M.W., Piff, P.K., Mendoza-Denton, R., Rheinschmidt, M.L., \& Keltner, D. (2012). Social class, solipsism, and contextualism: How the rich are different from the poor. Psychological Review, 119(3), 546-572. 
Kronrod, A., Grinstein, A., \& Wathieu, L. (2012). Go green! Should environmental messages be so assertive? Journal of Marketing, 76(1), 95-102.

Lalwani, A.K., \& Forcum, L. (2016). Does a dollar get you a dollar's worth of merchandise? The impact of power distance belief on price-quality judgments. Journal of Consumer Research, 43(2), 317-333.

Lin, Y.C., \& Chang, C.C.A. (2012). Double standard: The role of environmental consciousness in green product usage. Journal of Marketing, 76(5), 125-134.

Luchs, M.G., Brower, J., \& Chitturi, R. (2012). Product choice and the importance of aesthetic design given the emotion-laden trade-off between sustainability and functional performance. Journal of Product Innovation Management, 29(6), 903-916.

Luchs, M.G., Naylor, R.W., Irwin, J.R., \& Raghunathan, R. (2010). The sustainability liability: Potential negative effects of ethicality on product preference. Journal of Marketing, 74(5), $18-31$.

Madzharov, A.V., Block, L.G., \& Morrin, M. (2015). The cool scent of power: Effects of ambient scent on consumer preferences and choice behavior. Journal of Marketing, 79(1), $83-96$

Magee, J.C., \& Galinsky, A.D. (2008). Social hierarchy: The self-reinforcing nature of power and status. Academy of Management Annals, 2(1), 351-398.

Magee, J.C., \& Smith, P.K. (2013). The social distance theory of power. Personality and Social Psychology Review, 17(2), 158-186.

Mayer, F.S., \& Frantz, C.M. (2004). The connectedness to nature scale: A measure of individuals' feeling in community with nature. Journal of Environmental Psychology, 24(4), 503-515.

Newman, G.E., Gorlin, M., \& Dhar, R. (2014). When going green backfires: How firm intentions 
shape the evaluation of socially beneficial product enhancements. Journal of Consumer Research, 41(3), 823-839.

Olson, E.L. (2013). It's not easy being green: The effects of attribute trade-offs on green product preference and choice. Journal of the Academy of Marketing Science, 41(2), 171-184.

Oyserman, D. (2006). High power, low power, and equality: Culture beyond individualism and collectivism. Journal of Consumer Psychology, 16(4), 352-356.

Pancer, E., McShane, L., \& Noseworthy, T.J. (2017). Isolated environmental cues and product efficacy penalties: The color green and eco-labels. Journal of Business Ethics, 143(1), 159177.

Peloza, J., White, K., \& Shang, J. (2013). Good and guilt-free: The role of self-accountability in influencing preferences for products with ethical attributes. Journal of Marketing, 77(1), 104119.

Piff, P.K., Kraus, M.W., Côté, S., Cheng, B.H., \& Keltner, D. (2010). Having less, giving more: The influence of social class on prosocial behavior. Journal of Personality and Social Psychology, 99(5), 771-784.

Pitesa, M., \& Thau, S. (2013). Compliant sinners, obstinate saints: How power and self-focus determine the effectiveness of social influences in ethical decision making. Academy of Management Journal, 56(3), 635-658.

Prothero, A., Dobscha, S., Freund, J., Kilbourne, W.E., Luchs, M.G., Ozanne, L.K., et al. (2011). Sustainable consumption: Opportunities for consumer research and public policy. Journal of Public Policy \& Marketing, 30(1), 31-38.

Rai, T.S., \& Fiske, A.P. (2011). Moral psychology is relationship regulation: Moral motives for unity, hierarchy, equality, and proportionality. Psychological Review, 118(1), 57-75.

Romani, S., Grappi, S., \& Bagozzi, R.P. (2016). Corporate socially responsible initiatives and 
their effects on consumption of green products. Journal of Business Ethics, 135(2), 253-264.

Roux, C., Goldsmith, K., \& Bonezzi, A. (2015). On the psychology of scarcity: When reminders of resource scarcity promote selfish (and generous) behavior. Journal of Consumer Research, 42(4), 615-631.

Rucker, D.D., Dubois, D., \& Galinsky, A.D. (2011). Generous paupers and stingy princes: Power drives consumer spending on self versus others. Journal of Consumer Research, 37(6), 10151029.

Rucker, D.D., \& Galinsky, A.D. (2008). Desire to acquire: Powerlessness and compensatory consumption. Journal of Consumer Research, 35(2), 257-267.

Rucker, D.D., \& Galinsky, A.D. (2009). Conspicuous consumption versus utilitarian ideals: How different levels of power shape consumer behavior. Journal of Experimental Social Psychology, 45(3), 549-555.

Rucker, D.D., \& Galinsky, A.D. (2017). Social power and social class: Conceptualization, consequences, and current challenges. Current Opinion in Psychology, 18, 26-30.

Rucker, D.D., Galinsky, A.D., \& Dubois, D. (2012). Power and consumer behavior: How power shapes who and what consumers value. Journal of Consumer Psychology, 22(3), 352-368.

Rucker, D.D., Hu, M., \& Galinsky, A.D. (2014). The experience versus the expectations of power: A recipe for altering the effects of power on behavior. Journal of Consumer Research, 41(2), 381-396.

Sachdeva, S., Jordan, J., \& Mazar, N. (2015). Green consumerism: Moral motivations to a sustainable future. Current Opinion in Psychology, 6, 60-65.

Seo, J.Y., \& Scammon, D.L. (2017). Do green packages lead to misperceptions? The influence of package colors on consumers' perceptions of brands with environmental claims. Marketing Letters, 28(3), 357-369. 
Sexton, S.E., \& Sexton, A.L. (2014). Conspicuous conservation: The Prius halo and willingness to pay for environmental bona fides. Journal of Environmental Economics and Management, 67(3), 303-317.

Sheth, J.N., Sethia, N.K., \& Srinivas, S. (2011). Mindful consumption: A customer-centric approach to sustainability. Journal of the Academy of Marketing Science, 39(1), 21-39.

Shrum, L.J., McCarty, J.A., \& Lowrey, T.M. (1995). Buyer characteristics of the green consumer and their implications for advertising strategy. Journal of Advertising, 24(2), 71-82.

Smith, P.K., \& Trope, Y. (2006). You focus on the forest when you're in charge of the trees: Power priming and abstract information processing. Journal of Personality and Social Psychology, 90(4), 578-596.

Spiller, S.A., Fitzsimons, G.J., Lynch Jr, J.G., \& McClelland, G.H. (2013). Spotlights, floodlights, and the magic number zero: Simple effects tests in moderated regression. Journal of Marketing Research, 50(2), 277-288.

Straughan, R.D., \& Roberts, J.A. (1999). Environmental segmentation alternatives: A look at green consumer behavior in the new millennium. Journal of Consumer Marketing, 16(6), $558-575$.

Summers, C.A., Smith, R.W., \& Reczek, R.W. (2016). An audience of one: Behaviorally targeted ads as implied social labels. Journal of Consumer Research, 43(1), 156-178.

Tangari, A.H., Burton, S., \& Smith, R.J. (2015). Now that's a bright idea: The influence of consumer elaboration and distance perceptions on sustainable choices. Journal of Retailing, 91(3), 410-421.

Theotokis, A., \& Manganari, E. (2015). The impact of choice architecture on sustainable consumer behavior: The role of guilt. Journal of Business Ethics, 131(2), 423-437.

Thøgersen, J. (2005). How may consumer policy empower consumers for sustainable lifestyles? 
Journal of Consumer Policy, 28(2), 143-177.

Thøgersen, J., Haugaard, P., \& Olesen, A. (2010). Consumer responses to ecolabels. European Journal of Marketing, 44(11/12), 1787-1810.

Torelli, C.J., \& Shavitt, S. (2010). Culture and concepts of power. Journal of Personality and Social Psychology, 99(4), 703-723.

Tost, L.P., Wade-Benzoni, K.A., \& Johnson, H.H. (2015). Noblesse oblige emerges (with time): Power enhances intergenerational beneficence. Organizational Behavior and Human Decision Processes, 128, 61-73.

Trudel, R. (2019). Sustainable consumer behavior. Consumer Psychology Review, 2, 85-96. Van der Wal, A.J., van Horen, F., \& Grinstein, A. (2016). The paradox of 'green to be seen': Green high-status shoppers excessively use (branded) shopping bags. International Journal of Research in Marketing, 33(1), 216-219.

Van Vugt, M. (2009). Averting the tragedy of the commons using social psychological science to protect the environment. Current Directions in Psychological Science, 18(3), 169-173.

Wade-Benzoni, K.A., Hernandez, M., Medvec, V., \& Messick, D. (2008). In fairness to future generations: The role of egocentrism, uncertainty, power, and stewardship in judgments of intergenerational allocations. Journal of Experimental Social Psychology, 44(2), 233-245.

Wang, X., Wang, X., Fang, X., \& Jiang, Q. (2018). Power distance belief and brand personality evaluations. Journal of Business Research, 84(2), 89-99.

Webb, D.J., Mohr, L.A., \& Harris, K.E. (2008). A re-examination of socially responsible consumption and its measurement. Journal of Business Research, 61(1), 91-98.

Weber, E.U. (2015). Climate change demands behavioral change: What are the challenges? Social Research: An International Quarterly, 82(3), 561-580.

White, K., \& Simpson, B. (2013). When do (and don't) normative appeals influence sustainable 
consumer behaviors? Journal of Marketing, 77(2), 78-95.

Winterich, K.P., \& Zhang, Y. (2014). Accepting inequality deters responsibility: How power distance decreases charitable behavior. Journal of Consumer Research, 41(2), 274-293.

Yan, L., Keh, H.T., \& Chen, J. (2019). The rise of the middle class: The curvilinear effect of social class on green consumption. Working paper.

Zabkar, V., \& Hosta, M. (2013). Willingness to act and environmentally conscious consumer behaviour: Can prosocial status perceptions help overcome the gap? International Journal of Consumer Studies, 37(3), 257-264.

Zaval, L., Markowitz, E.M., \& Weber, E.U. (2015). How will I be remembered? Conserving the environment for the sake of one's legacy. Psychological Science, 26(2), 231-236.

Zhang, Y., Winterich, K.P., \& Mittal, V. (2010). Power distance belief and impulsive buying. Journal of Marketing Research, 47(5), 945-954.

Zhong, C.B., Magee, J.C., Maddux, W.W., \& Galinsky, A.D. (2006). Power, culture, and action: Considerations in the expression and enactment of power in East Asian and Western societies. In Y.-R. Chen (Ed.), National Culture and Groups (Research on Managing Groups and Teams, Volume 9) (pp. 53-73). Emerald Group Publishing. 
Figure 1. Conceptual Framework

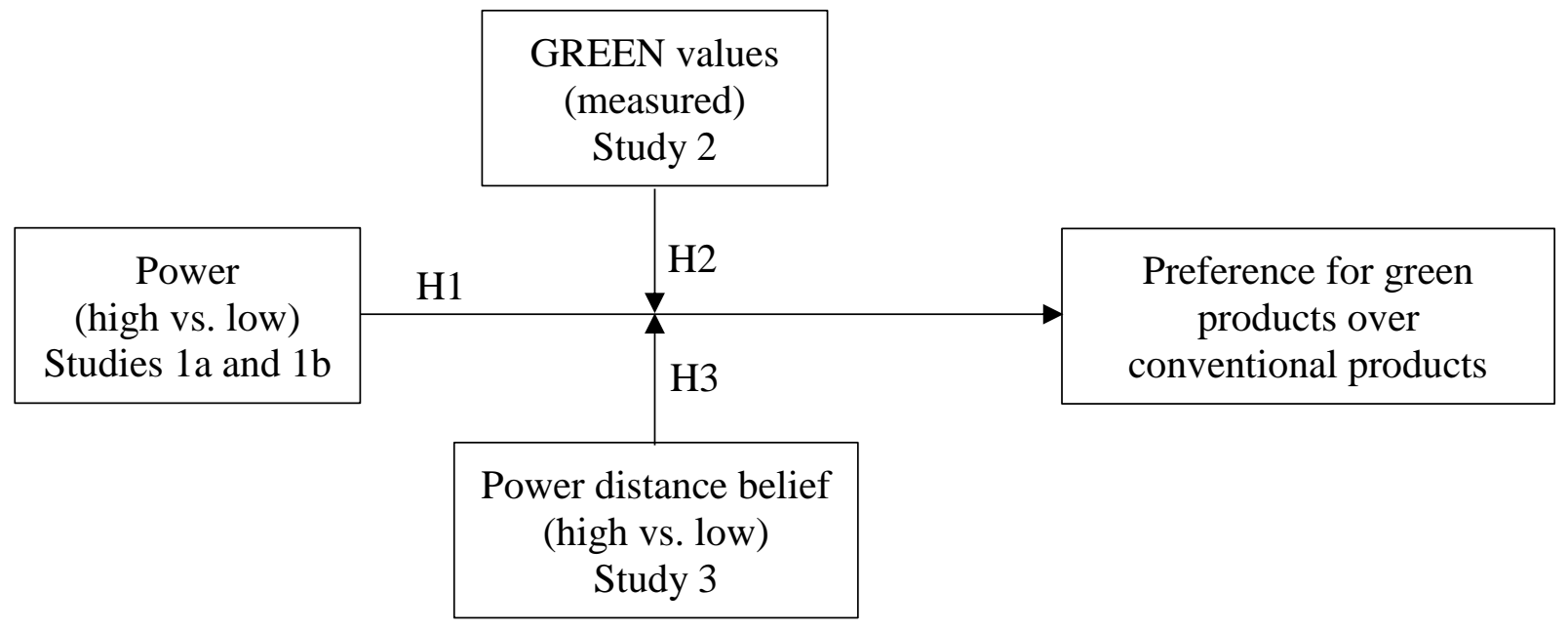


Figure 2. The Main Effects of Power on Purchase Intention (Study 1b)

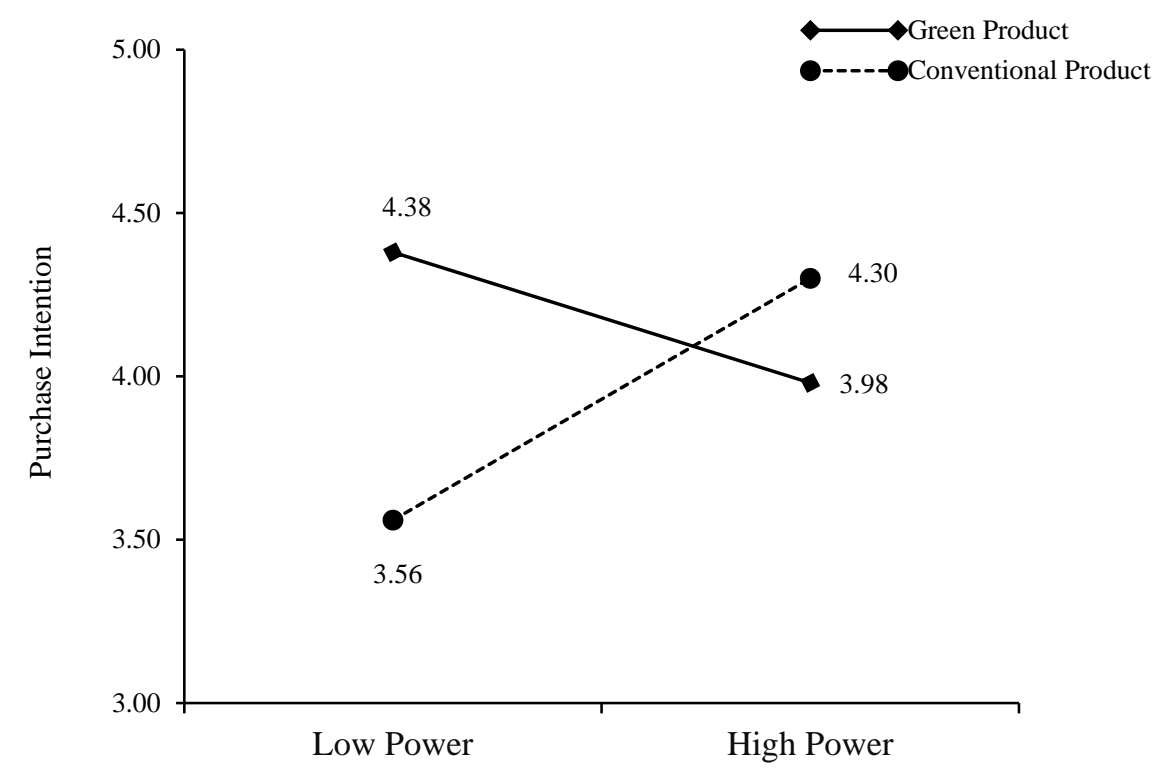

Figure 3. The Moderating Effects of GREEN values (Study 2)

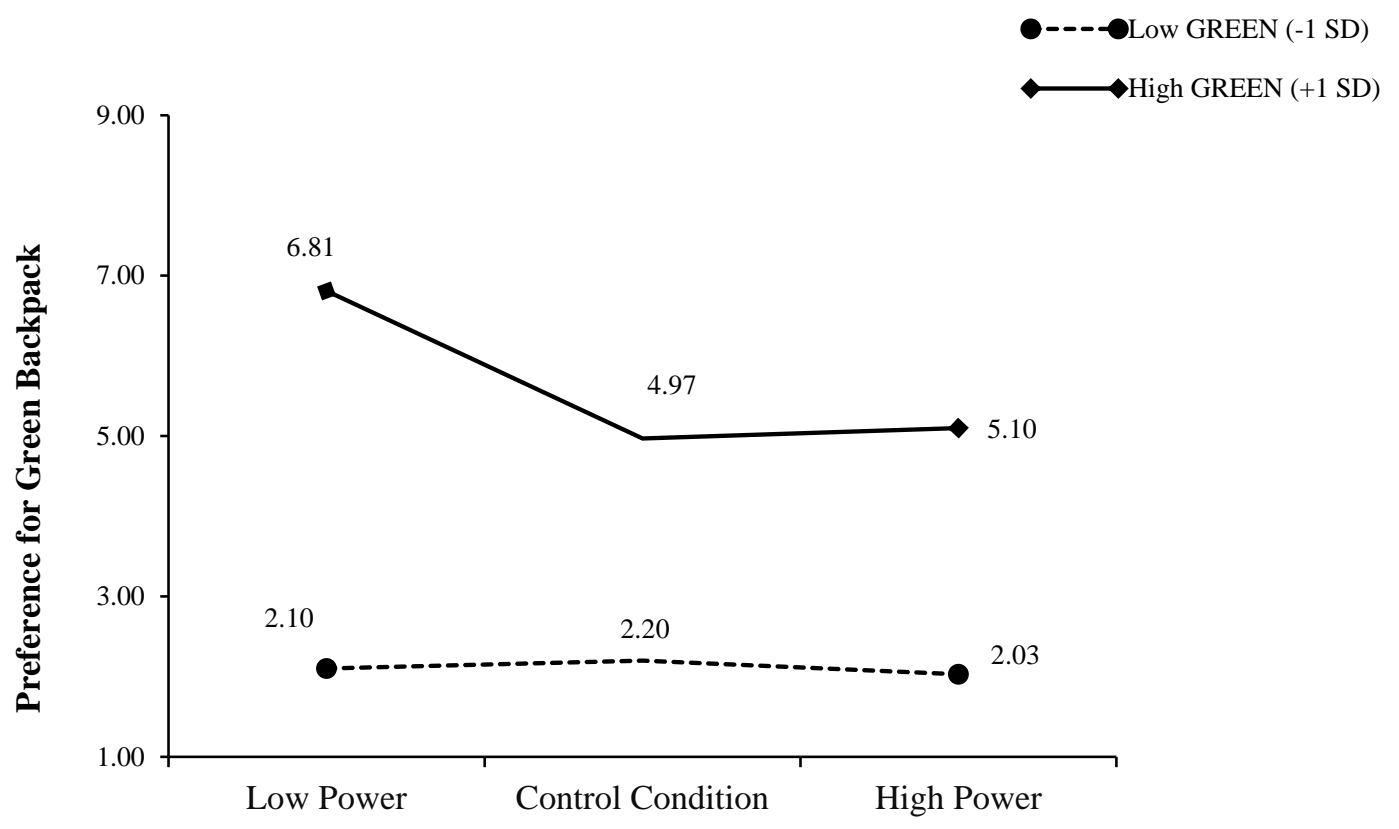


Figure 4a. Interaction Effects of Power and PDB on Purchase Intention (Study 3)
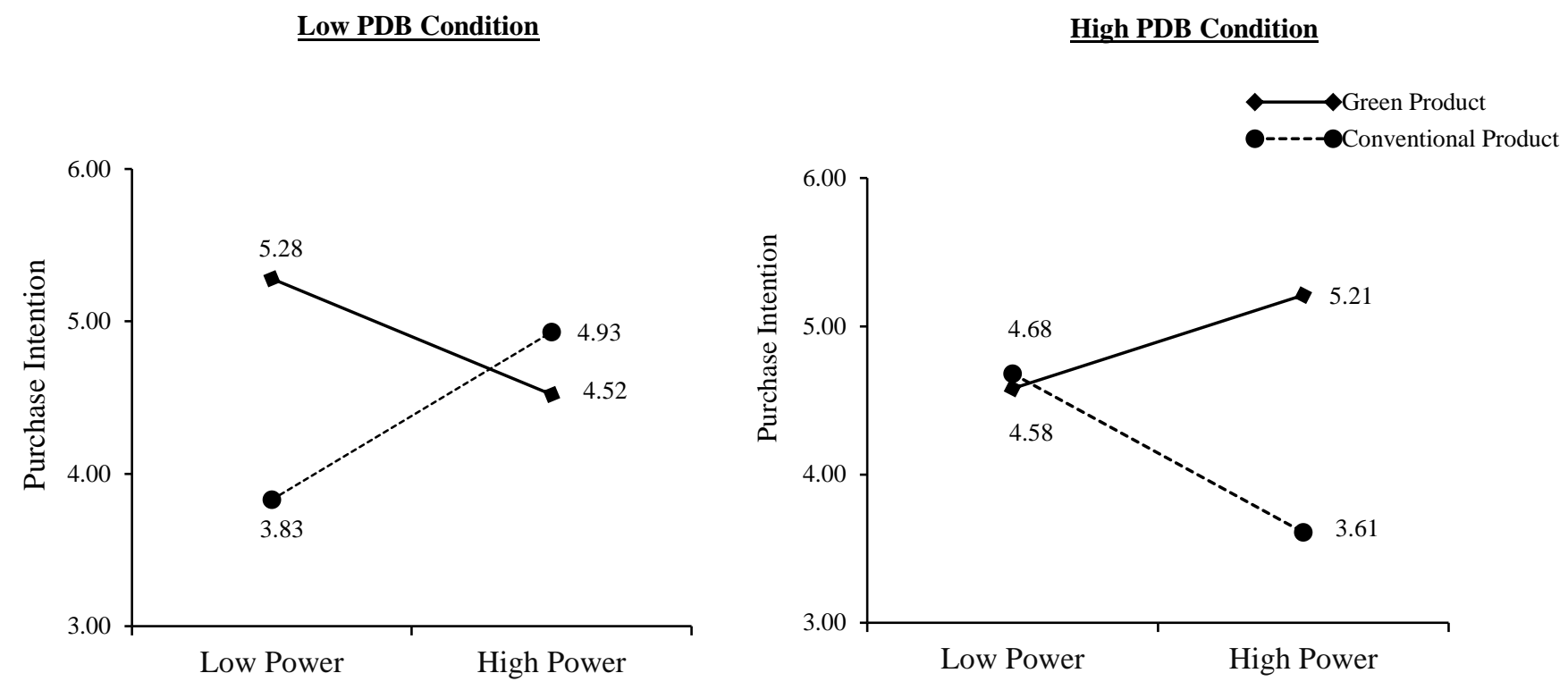

Figure 4b. Interaction Effects of Power and PDB on Willingness to Pay (Study 3)

$\underline{\text { Low PDB Condition }}$

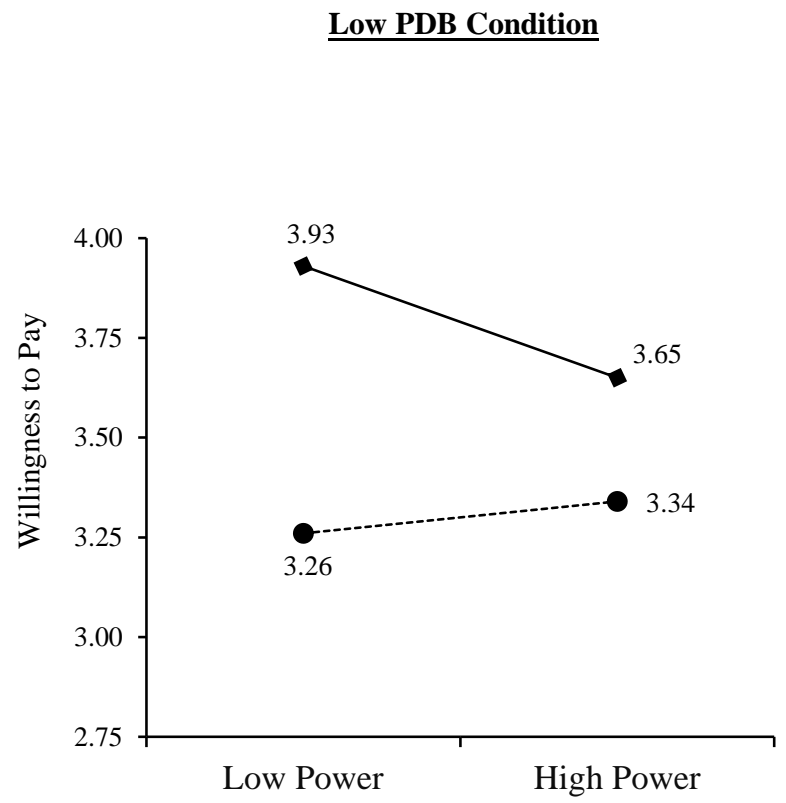

High PDB Condition

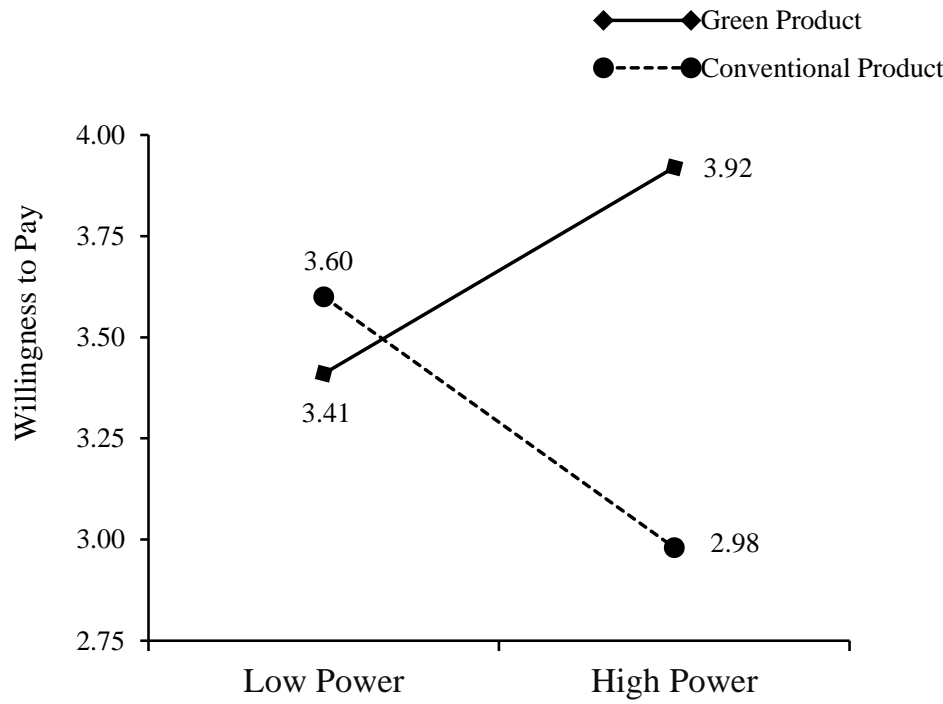


Table 1. Moderated Hierarchical Regression Analysis (Study 2)

\begin{tabular}{|c|c|c|c|c|c|c|}
\hline \multirow{2}{*}{ Variables } & \multicolumn{2}{|c|}{ Model 1} & \multicolumn{2}{|c|}{ Model 2} & \multicolumn{2}{|c|}{ Model 3} \\
\hline & $\beta$ & t-value & $\beta$ & t-value & $\beta$ & t-value \\
\hline \multicolumn{7}{|l|}{ Control Variables } \\
\hline Gender & .11 & $1.73^{\wedge}$ & .09 & 1.55 & .09 & $1.90^{\wedge}$ \\
\hline Age & -.05 & -.05 & -.06 & -.90 & -.07 & -1.40 \\
\hline Education & -.09 & -1.42 & -.09 & -1.39 & -.10 & $-2.05^{*}$ \\
\hline Income & -.00 & -.06 & -.02 & -.34 & -.03 & -.69 \\
\hline \multicolumn{7}{|l|}{ Focal Predictors } \\
\hline Dummy 1 (D1) & & & -.17 & $-2.46^{*}$ & -.13 & $-2.53^{*}$ \\
\hline Dummy 2 (D2) & & & -.15 & $-2.17^{*}$ & -.14 & $-2.54^{*}$ \\
\hline GREEN values (GREEN) & & & & & .84 & $9.64^{* * *}$ \\
\hline \multicolumn{7}{|l|}{ Interactions } \\
\hline D1 × GREEN & & & & & -.24 & $-3.34^{* *}$ \\
\hline D2 $\times$ GREEN & & & & & -.17 & $-2.52^{*}$ \\
\hline$R^{2}$ & & .02 & & .30 & & .32 \\
\hline$d f$ & & $(4,270)$ & & $(6,268)$ & & $(9,265)$ \\
\hline Overall Model (F-value) & & 1.56 & & $2.26^{*}$ & & $22.07^{* * *}$ \\
\hline$R^{2}$ Change Statistics & & & & $.03^{*}$ & & $.38^{* * *}$ \\
\hline
\end{tabular}

Note: ${ }^{* * *} p<.001,{ }^{* *} p<.01,{ }^{*} p<.05,{ }^{\wedge} p<.10 . \mathrm{N}=275 . \beta=$ Standardized coefficient. 